\title{
Comparative study of Mentha species growing wild in Egypt: LC-ESI-MS analysis and chemosystematic significance
}

\author{
Mona M. Marzouk ${ }^{1}$, Sameh R. Hussein ${ }^{1 *}$, Ahmed Elkhateeb ${ }^{1}$, Mona El-shabrawy ${ }^{1}$, El-Sayed S. Abdel-Hameed ${ }^{2,3}$, \\ Salwa A. Kawashty ${ }^{1}$ \\ ${ }^{1}$ Phytochemistry and Plant Systematics Department, National Research Centre, 33 El Bohouth St., Dokki, Giza, P. O. 12622, Egypt. \\ ${ }^{2}$ Laboratory of Medicinal Chemistry, Theodor Bilharz Institute, Giza, Egypt. \\ ${ }^{3}$ Chemistry Department, Faculty of Science, Taif University, Saudi Arabia.
}

\section{ARTICLE INFO \\ Article history: \\ Received on: 05/03/2018 \\ Accepted on: 09/05/2018 \\ Available online: $31 / 08 / 2018$}

\section{Key words:}

Mentha longifolia,

Mentha pulegium, LC-

ESI-MS, Flavonoids,

Chemosystematics.

\begin{abstract}
Mentha longifolia (L.) Huds. and Mentha pulegium L. are growing wild in Egyptian flora, they have many biological activities and commonly used as traditional herbal medicines. The aqueous methanolic extracts of the two Egyptian species were subjected to a comparative study for the first time using the LC-ESI-MS fingerprint. 43 compounds belonging to different chemical classes (flavone, flavonol, flavanone, $C$-glycosylflavone, phenolic acids and their glycosides) have been identified. The identified compounds can be used as chemosystematic markers and further our knowledge of the infraspecific relationship between the studied species. Further isolation and in vitro testing of metabolites will provide more evidence for the possible uses of Mentha sp.
\end{abstract}

\section{INTRODUCTION}

Lamiaceae, previously called Labiatae, is the mint family of flowering plants consisting of 236 genera and more than 7,000 species. It is one of the largest plant families (Hajlaoui et al., 2009). Due to the ease of cultivation, many members of Lamiaceae are widely cultivated for their aromatic qualities. Mint plants are used in medicine, food, and perfume industry. They are used in folk medicine as anti-inflammatory, antiemetic, antispasmodic, carminative, choleretic, emmenagogue, diaphoretic, and have antimicrobial activities (Naghibi et al., 2005). Mentha is a genus of about 25 species of flowering plants which distributed across Africa, Asia, Europe, North America, and Australia (Mustafa et al., 2005). These species are commercially grown for its essential oil content. In the Egyptian flora, the genus Mentha is represented by

\section{${ }^{*}$ Corresponding Author}

Sameh R. Hussein, Phytochemistry and Plant Systematics Department, National Research Centre, 33 El Bohouth St., Dokki, Giza, P. O. 12622, Egypt.E-mail:sameh_reda@hotmail.com two species; Mentha longifolia (L.) Huds. and Mentha pulegium L. (Mustafa et al., 2006).

The phytochemical constituents reported from $M$. longifolia and M. pulegium are flavonoids (Sharaf et al., 1999; Guvenalp et al., 2015; Taamalli et al., 2015), phenolic acids (Guvenalp et al., 2015; Taamalli et al., 2015), essential oils (El-Ghorab, 2006), dihydrochalcone glycosides (Guvenalp et al., 2015 ) and $\beta$-sitosterol glycosides (Ali et al., 2002). Flavonoids are the major reported metabolites, they occurred mostly as flavones and their glycosides (Baris et al., 2011; Orhan et al., 2012; Gulluce et al., 2013; Guvenalp et al., 2015; Taamalli et al., 2015), while $C$-glycosyl flavones (Sharaf et al., 1999), methoxyflavone aglycones (Zaidi et al., 1997; Taamalli et al., 2015), flavanones and their glycosides (Krzyzanowska et al., 2011; Taamalli et al., 2015), and flavonol glycosides (Akroum et al., 2009) were also reported.

M. longifolia and M. pulegium are previously reported for their antioxidant (El-Ghorab, 2006; Hajlaoui et al., 2009), cytotoxic (Shirazi et al., 2009; Orhan et al., 2012; Al-Ali et al., 
2013; Gulluce et al., 2015), and antimicrobial (Akroum et al., 2009, Baris et al., 2011) activities.

There are no studies have been reported on phenolic constituents of the two wild Mentha species from Egypt. The previous phytochemical study on $M$. pulegium was carried out on a cultivated species (Shalaby et al., 2000). Therefore, the aim of the current study was to perform a full characterization of the phytochemicals existing in the aqueous methanolic extracts of $M$. longifolia and M. pulegium, growing in Egypt, using LC-ESI-MS analysis, in an attempt to tentatively identify the polar compounds present in their extracts. In addition, the chemosystematic significance of the detected phenolics was also discussed.

\section{EXPERIMENTAL}

\section{Plant material}

M. longifolia was collected from west El Fayoum canal bank, Egypt in April 2016 while M. pulegium was collected from irrigated canal from Baharryia Oasis, Egypt in March 2016 and authenticated by Dr. Mona M. Marzouk and Dr. Sameh R. Hussein, Department of Phytochemical and Plant Systematics, NRC. A voucher specimen (sn. 3402 and 3256, respectively) were deposited in the Herbarium of NRC (CAIRC, Cairo, Egypt).

\section{Extraction}

$50 \mathrm{~g}$ of each species were air dried and extracted with $70 \%$ methanol-water at room temperature twice each for two days. The crude filtered extracts were concentrated under reduced pressure in a rotary evaporator till dryness and preserved in $-80^{\circ} \mathrm{C}$ freezer until LC-MS analysis.

\section{LC-ESI-MS analysis}

The LC-ESI-MS analysis of the studied species was carried out on HPLC (Waters Alliance 2695) and mass spectrometry (Waters 3100) and followed the same method of Hussein et al. (2018).

\section{RESULTS AND DISCUSSION}

\section{LC-ESI-MS analysis}

43 compounds were characterized and identified from M. longifolia and M. pulegium extracts (Table 1; Figure 1(a, b)). Peaks 2 and 3 revealed the same fragments; $m / z$ 179, 135, indicating the presence of caffeoyl hexoide derivatives. Compound 3 gave molecular ion peak at $\mathrm{m} / \mathrm{z} 665$ and fragments at $\mathrm{m} / \mathrm{z} 503$

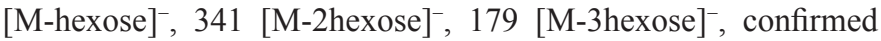
that the three hexose moieties were connected to different phenolic hydroxyl groups.

Peak 4 (m/z 191) was characterized as citric acid. Its spectrum showed a fragment ion at $\mathrm{m} / \mathrm{z} 111$ which corresponds to the loss of $\mathrm{H}_{2} \mathrm{O}$ and $\mathrm{CO}_{2}$ molecules $\left[\mathrm{M}-\mathrm{H}-\mathrm{CO}_{2}-2 \mathrm{H}_{2} \mathrm{O}\right]^{-}$(Taamalli et al., 2015).

Quinic acid was presented as peak $6(\mathrm{~m} / \mathrm{z} 191)$ in both extracts, confirmed by the presence of the fragment ion at $\mathrm{m} / \mathrm{z} 127$ [M-H-CO-2 $\left.\mathrm{H}_{2} \mathrm{O}\right]^{-}$(Taamalli et al., 2015). This compound was identified in various Mentha spp. (Taamalli et al., 2015; Xu et al., 2017).

Peaks 8, 11 \& 12 produce the same molecular ion peak at $m / z 353$ and identified as chlorogenic acid derivatives. The product ion at $\mathrm{m} / \mathrm{z} 191$ [quinic acid-H] ${ }^{-}$, corresponding to quinic acid and another fragment ion at $\mathrm{m} / \mathrm{z} 179$ [caffeic acid$\mathrm{H}]^{-}$, corresponding to caffeic acid. Additional fragment ion was observed in compound 12 at $\mathrm{m} / \mathrm{z} 173$ [quinic acid- $\left.\mathrm{H}_{2} \mathrm{O}-\mathrm{H}\right]^{-}$, which is characteristic to 4-O-caffeoylquinic acid (Ncube et al., 2014). It was identified in both extracts under study. Also, compounds $\mathbf{8}$ and $\mathbf{1 1}$ were identified as cis- and trans-3-O-caffeoylquinic acid, respectively. They were identified in $M$. longfolia only. Other chlorogenic acids were shown for peaks 10, 15, 39 and 40. Compounds 10 and $\mathbf{1 5}$ have the same molecular ions at $\mathrm{m} / \mathrm{z} 337$ and fragmentation ions at $\mathrm{m} / \mathrm{z} 191$ and 119 [M-H-Coumaroyl]',

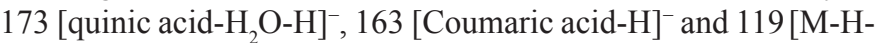
$\left.\mathrm{CO}_{2}\right]^{-}$. They have been identified as coumaroyl quinic acids (Ncube et al., 2014). Compound 39 with a molecular ion at $m / z 487$ and fragments 308 [M-H-caffeoyl] and 179 [M-H-deoxyhexosehexose $]^{-}$, confirmed the presence of caffeoyl hexose-deoxyhexose (Chen et al. 2011). While compound 40 was identified as 3,4-di-Ocaffeoylquinic acid, confirmed the presence of fragment ions 353 [M-H-caffeoyl] $]^{-}, 191$ [quinic acid-H] $^{-}, 179$ [caffeic acid-H] $]^{-}, 173$ [quinic acid- $\left.\mathrm{H}_{2} \mathrm{O}-\mathrm{H}\right]^{-}$(Ncube et al., 2014).

Peak 9 with a molecular ion $\mathrm{m} / \mathrm{z} 609$ showed a fragment ion at $\mathrm{m} / \mathrm{z} 447$ after the loss of hexose moiety [M-H-162] $]^{-}$The fragment ions at $m / z 327$ [M-H-162-120] $]^{-}$, and at $m / z 357$ [M-H$162-90]^{-}$, confirmed the characteristic of luteolin $8-C$-hexoside (Farag et al., 2016). Therefore, compound 9 was assigned as luteolin 6- $C$-hexoside- $O$-hexoside. Another luteolin diglycosides was detected at peak $36(\mathrm{~m} / \mathrm{z} 593)$, which exhibited a fragment ion at $\mathrm{m} / z 285$ [M-H-(rhamnose+hexose) $]^{-}$. No fragments were observed at $\mathrm{m} / \mathrm{z} 431$ and/or 447, indicated that both glycosyl moieties were connected to the same phenolic hydroxyl group (Marzouk et al., 2016). Thus, compound 36 identified as luteolin$O$-rhamnose-hexose.

Compound 13 produced a molecular ion peak at $\mathrm{m} / \mathrm{z} 179$ and is identified as caffeic acid, confirmed by the mass fragments and $R t$ of the authentic standard.

Tuberonic acid hexoside (peak 14) with $\mathrm{m} / \mathrm{z} 387$ gave fragments at $m / z 207$, which corresponds to the aglycone after a loss of hexose $[\mathrm{M}-\mathrm{H}-162]^{-}$. Tuberonic acid glucoside was previously observed in the extract of $M$. pulegium (Taamalli et al., 2015).

Peak 16 at $\mathrm{m} / \mathrm{z} 593$ was characterized as vicenin-2 (apigenin 6,8-di- $C$-glucoside), confirmed by the appearance of fragment ions at $m / z 503$ [M-H-90] $]^{-}$and $m / z 473$ [M-H-90-120] as well as by comparing with authentic.

Peak 17, at $\mathrm{m} / \mathrm{z} 305$ revealed a main fragment ion at $\mathrm{m} / \mathrm{z} 225$ [M-H-80] $]^{-}$, after a loss of sulphate moiety, which was assigned to be 12-hydroxyjasmonate sulphate, confirmed by its fragmentation patterns in the literature (Kapp et al., 2013; Taamalli et al., 2015; Xu et al., 2017).

Peaks 18, 19, 24, 26 and 37, showing molecular ion peaks at $\mathrm{m} / \mathrm{z} 595,593,579,577$ and 591, yielded fragment ions at $\mathrm{m} / z 287,285,271,269$ and 283, respectively, after loss of a disaccharide moiety (rhamnose+hexose) [M-H-308] $]^{-}$These peaks were observed in both chromatograms of the two studied species, except peak 18, which present in M. pulegium only. These compounds were proposed to be 7-O-rutinoside of eriodictyol, luteolin, naringenin, apigenin, and acacetin, respectively, 
compared with the mass fragments of standards and in the literature (Taamalli et al., 2015). The five compounds have been previously reported in M. pulegium extract (Taamalli et al., 2015) as well as in the genus Mentha and other Lamiaceae species (Areias et al., 2001; Aksit et al., 2014; Xu et al., 2017), while compounds 19 and 26 were previously reported in M. longifolia with highly antimutagenic properties (Orhan et al., 2012; Gullece et al., 2013).

Table 1: Tentative identification of phenolic compounds in M. longifolia and M. pulegium.

\begin{tabular}{|c|c|c|c|c|c|c|c|}
\hline \multirow{2}{*}{ No. } & \multirow{2}{*}{$R t$ (min) } & \multirow{2}{*}{$\mathbf{M}$} & \multirow{2}{*}[\mathbf{M}-\mathbf{H}]{$^{-}$} & \multirow{2}{*}{$m / z$ fragments } & \multicolumn{3}{|c|}{ Tentative identification } \\
\hline & & & & & Compounds & M. longifolia & M. pulegium \\
\hline 1 & 2.17 & 518 & 517 & $503,403,387,289,273,175,159,131$ & Unkown & - & + \\
\hline 2 & 2.67 & 990 & 989 & $665,503,341,179,135$ & Caffeoyl hexosides derivatives & + & - \\
\hline 3 & 2.7 & 666 & 665 & $503,341,179,135$ & Caffeoyl trihexoside & + & + \\
\hline 4 & 3.25 & 192 & 191 & 111 & Citric acid ${ }^{\$}$ & + & + \\
\hline 5 & 4.08 & 317 & 316 & 194,128 & Unknown & + & + \\
\hline 6 & 4.49 & 192 & 191 & $173,128,85$ & Quinic acid ${ }^{\$}$ & + & + \\
\hline 7 & 15.61 & 409 & 408 & 241 & Unknown & + & + \\
\hline 8 & 17.03 & 354 & 353 & $191,179,173,135$ & cis 3-Caffeoyl quinic acid ${ }^{\$}$ & + & - \\
\hline 9 & 17.62 & 610 & 609 & $447,357,327$ & Luteolin 6-C-hexoside- $O$-hexoside & - & + \\
\hline 10 & 20.71 & 338 & 337 & $173,163,119$ & 4-p-Coumaroyl quinic acid $\$$ & + & + \\
\hline 11 & 22.21 & 354 & 353 & $191,179,161,108$ & trans 3-Caffeoyl quinic acid ${ }^{\$}$ & + & - \\
\hline 12 & 23.30 & 354 & 353 & $191,179,173,135$ & 4-Caffeoyl quinic acids & + & + \\
\hline 13 & 24.13 & 180 & 179 & $135,134,89,78$ & Caffeic acid* & + & + \\
\hline 14 & 25.38 & 388 & 387 & $207,163,101$ & Tuberonic acid glucoside $\$$ & + & + \\
\hline 15 & 26.84 & 338 & 337 & $191,173,163$ & 5-p-Coumaroyl quinic acid ${ }^{\$}$ & + & - \\
\hline 16 & 27.22 & 594 & 593 & 473,503 & Apigenin 6,8 -di- $C$-glucoside (Vicenin)* & + & + \\
\hline 17 & 29.98 & 306 & 305 & 225,97 & 12-Hydroxyjasmonate sulfate ${ }^{s}$ & + & + \\
\hline 18 & 31.98 & 596 & 595 & $287,151,135,103$ & Eriocitrin ( Eriodictyol-7-O-rutinoside) ${ }^{\$}$ & - & + \\
\hline 19 & 33.90 & 594 & 593 & 285 & Luteolin 7-O-rutinoside* & + & + \\
\hline 20 & 34.4 & 610 & 609 & 301 & Quercetin- $O$-rhamno-hexoside & + & - \\
\hline 21 & 34.65 & 448 & 447 & $285,179,151$ & Luteolin 7-O-glucoside* & + & + \\
\hline 22 & 35.1 & 567 & 566 & 463,301 & Quercetin $O$-benzoylhexoside & + & - \\
\hline 23 & 35.18 & 464 & 463 & 301 & Quercetin 3-O-glucoside* & + & + \\
\hline 24 & 35.49 & 580 & 579 & 271 & Narirutin (Naringenin 7-rutinoside) ${ }^{\$}$ & + & + \\
\hline 25 & 36.4 & 462 & 461 & 285 & Luteolin 7-O-glucuronide* & + & + \\
\hline 26 & 37.16 & 578 & 577 & 269 & Apigenin 7-O-rutinoside* & + & + \\
\hline 27 & 37.9 & 610 & 609 & 301 & Quercetin 3-rutinoside* & + & + \\
\hline 28 & 38.24 & 448 & 447 & 301 & Quercetin 3-O-rhamnoside* & + & - \\
\hline 29 & 38.5 & 432 & 431 & 269 & Apigenin 7-O-glucoside* & + & + \\
\hline 30 & 39.08 & 538 & 537 & $493,359,295,197,161$ & Lithospermic acid $\$$ & + & + \\
\hline 31 & 40.08 & 550 & 549 & 387,207 & Medioresinol- $O$-hexoside & + & - \\
\hline 32 & 40.58 & 806 & 805 & $739,717,659,637,357,193,175$ & Unknown & - & + \\
\hline 33 & 41.9 & 718 & 717 & $519,393,321,295$ & Salvianolic acid $\mathrm{B}^{\$}$ & + & + \\
\hline
\end{tabular}




\begin{tabular}{|c|c|c|c|c|}
\hline 34 & 42.7 & 462 & 461 & 285 \\
\hline 35 & 44.42 & 564 & 563 & 387,207 \\
\hline 36 & 45.09 & 594 & 593 & 285 \\
\hline 37 & 45.67 & 592 & 591 & 283 \\
\hline 38 & 46.26 & 286 & 285 & 151,133 \\
\hline 39 & 46.67 & 488 & 487 & $308,179,135$ \\
\hline 40 & 47.67 & 516 & 515 & $353,191,179,173,135$ \\
\hline 41 & 49.85 & 330 & 329 & $314,299,271,243,179$ \\
\hline 42 & 50.68 & 360 & 359 & $329,315,299$ \\
\hline 43 & 51.02 & 270 & 269 & $225,151,119$ \\
\hline 44 & 52.10 & 360 & 359 & $314,299,284$ \\
\hline 45 & 54.02 & 374 & 373 & $359,344,329,314,285$ \\
\hline 46 & 55.44 & 360 & 359 & $344,329,269$ \\
\hline 47 & 55.61 & 360 & 359 & $329,315,285$ \\
\hline
\end{tabular}

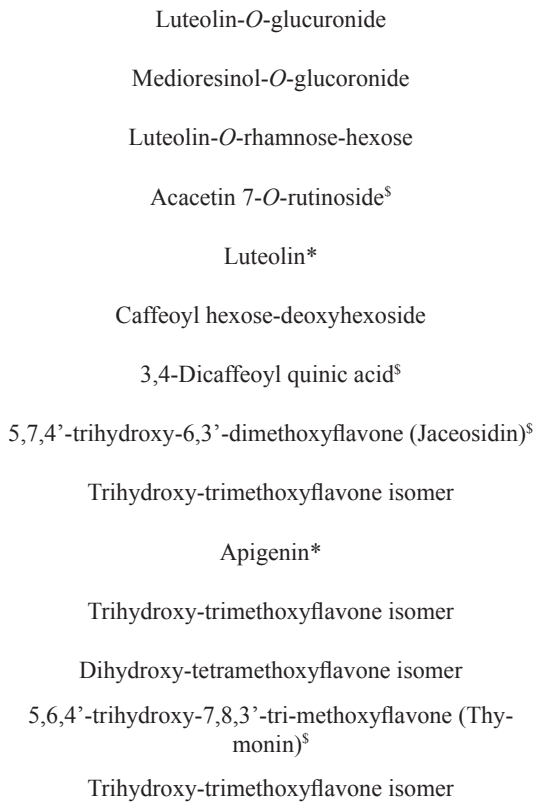

*Compounds identified by comparing their retention times and mass spectrum with the authentic.

${ }^{\$}$ Compounds identified based on the mass spectral data cited in the literature.

Peaks 20 and 27 presented the same molecular ion peak at $\mathrm{m} / z 609$ and the same fragment ion at $\mathrm{m} / \mathrm{z} 301$, after the loss of disaccharide moiety (rhamnose+hexose). No fragments were observed at $\mathrm{m} / \mathrm{z} 447$ or 463 , indicated that both glycosyl moieties were connected to the same phenolic hydroxyl group (Marzouk et al., 2016). Compound $\mathbf{2 0}$ was identified as quercetin- $O$ rhamnose-hexose, while compound $\mathbf{2 7}$ was identified as quercetin 3-O-rutinoside, confirmed by direct comparison with the standard.

Peak 21 was detected at $m / z 447$ in both extracts and produced fragment at $\mathrm{m} / \mathrm{z} 285$ [M-H-hexose]. This compound is assigned to be luteolin 7-O-glucoside, by comparing the mass fragmentation and $R t$ of standard, which previously isolated from M. pulegium (Taamalli et al., 2015) and M. longifolia (Orhan et al., 2012; Guvenalp et al., 2015).

Compound 22 at $\mathrm{m} / \mathrm{z} 567$ revealed a fragment ion at $\mathrm{m} / \mathrm{z}$ $463[\mathrm{M}-\mathrm{H}-104]^{-}$which corresponds to quercetin hexoside, after the loss of benzoyl moiety. Another fragment at $\mathrm{m} / \mathrm{z} 301$ [M-H104-162] $]^{-}$was corresponding to quercetin aglycone by the loss of a hexose moiety. Thus, compound $\mathbf{2 2}$ could be identified as quercetin $O$-benzoylhexoside.

Peaks 23 and 28 at $m / z 463$ and 447 revealed the same fragment ion at $m / z 301$ and were identified as quercetin 3-O-glucoside and quercetin 3-O-rhamnoside, respectively. Their mass fragmentation and $R t$ are matching with the authentic standard.

Peaks 25 and $34(\mathrm{~m} / \mathrm{z}$ 461) was identified as luteolin$\mathrm{O}$-glucuronide, confirmed by losing of glucuronic acid [M-H176] $]^{-}$and a fragment ion at $\mathrm{m} / \mathrm{z} 285$, which corresponding to luteolin aglycone. Both compounds were detected in the two Mentha species. Compound $\mathbf{2 5}$ was further identified as luteolin 7-O-glucuronide by comparing the mass fragmentation and $R t$ with standards. This compound has been previously reported in M. pulegium (Taamalli et al., 2015) and M. longifolia (Guvenalp et al., 2015).
Peak 29, at $m / z 431$ revealed the main fragment ion at 269 which corresponds to apigenin aglycone by the loss of a hexose moiety [M-H-162]-. This compound was confirmed to be apigenin 7-O-glucoside by comparison with standard and was previously reported for M. pulegium (Taamalli et al., 2015) and M. longifolia (Gullece et al., 2015).

Lithospermic acid (peak 30) was observed in the two extracts at Rt 39.08 and showed a molecular ion peak $[\mathrm{M}-\mathrm{H}]^{-}$at $m / z$ 537, confirmed by fragments 493,359, 295, 197 and 161 (Taamalli et al., 2015). It has been previously reported in M. pulegium, some Mentha species and other species of Lamiaceae (Taamalli et al., 2015). This compound exhibited a strong cytotoxicity against both MCF-7/wt and MCF-7/Adr human breast cancer cells (Berdowska et al., 2013).

Medioresinol- $O$-hexoside and medioresinol- $O$ glucoronide were observed at peaks $\mathbf{3 1}$ and $\mathbf{3 5}$ with molecular ions at $\mathrm{m} / \mathrm{z} 549$ and 563, respectively. Both peaks yielded fragment at $\mathrm{m} / \mathrm{z} 387$, corresponding to a medioresinol moiety, after the loss of a hexose moiety for compound $\mathbf{3 1}$ and the loss of a glucoronide moiety for compound $\mathbf{3 5}$. Medioresinol was previously reported in some Mentha species and other of family Lamiaceae (Kapp, 2015).

Compound $33(\mathrm{~m} / \mathrm{z} 717)$ was identified as salvianolic acid B, confirmed by the fragmentation patterns $(\mathrm{m} / \mathrm{z} 519,393$, 295, 321) with the literature (Kapp et al., 2013; Kapp, 2015). It was previously detected in M. longifolia (Krzyzanowska et al., 2011) and found to possess a potent anti-oxidative competence (Zhao et al., 2008).

Peak 38 at $m / z 285$ was suggested to be luteolin, confirmed by the comparison with the authentic standard and the presence of fragment ions at 151 and 133 after a cleavage of A and B-rings, respectively. In the same manner, compound 44 at 51.02 $(\mathrm{m} / z$ 269) was identified as apigenin on the basis of the authentic standard. 

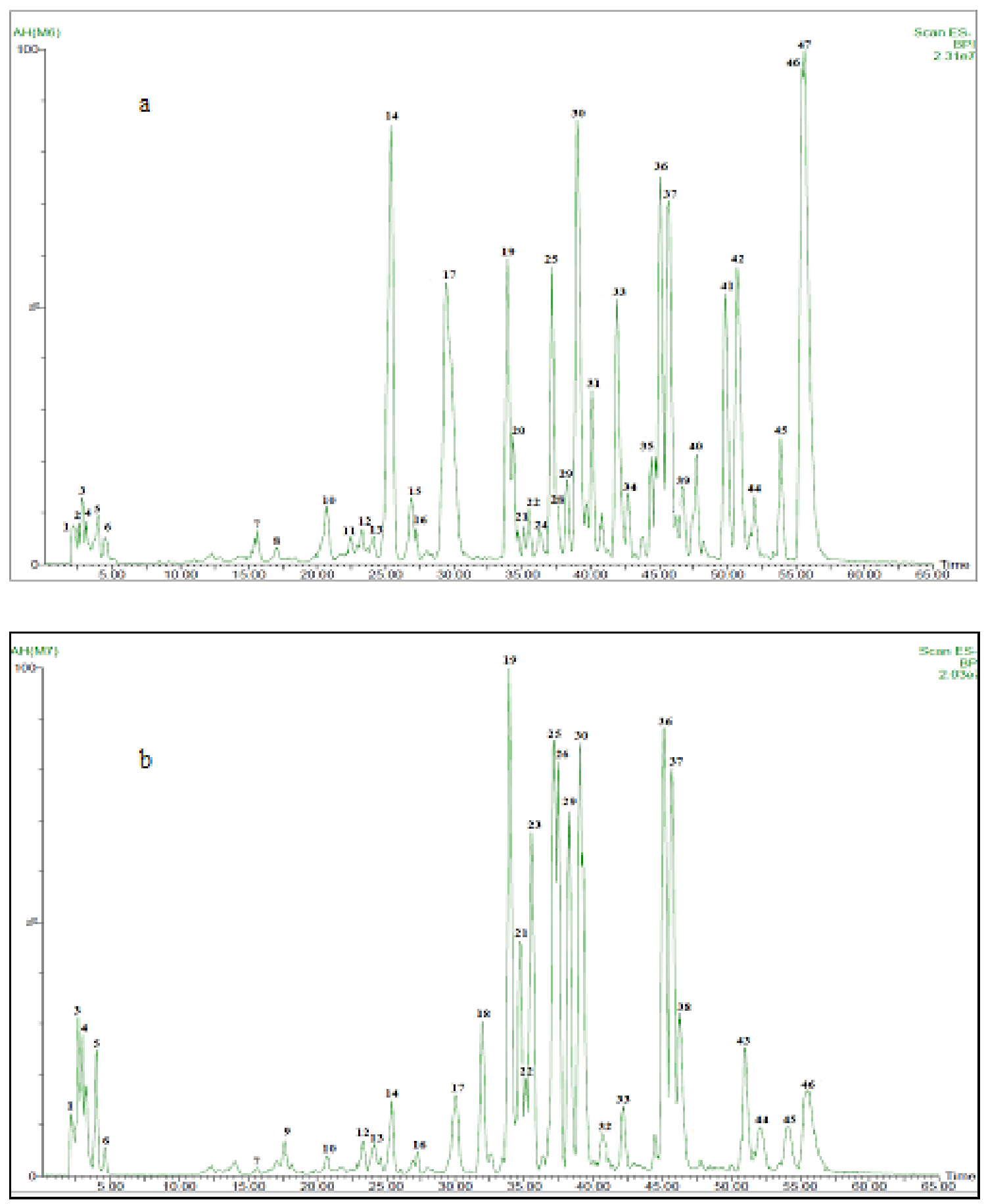

Fig. 1: LC-ESI-MS chromatogram of M. longifolia (a) and M. pulegium (b).

Several methylated flavones were observed at peaks 41, 42 and 44-47, exhibiting the loss of $\mathrm{CH}_{3}$ (15 amu) from the methoxy groups, which is previously detected in the two investigated species (Zaidi et al., 1998), other Mentha species (Voirin et al., 1999; Xu et al., 2017) and various species of family Lamiaceae (Tomás-Barberán et al., 1988). On the bases of the mass fragments; peak $41(\mathrm{~m} / \mathrm{z} 329)$ was identified as a trihydroxydimethoxyflavone isomer, peak $45(\mathrm{~m} / \mathrm{z} 373)$ was identified as a dihydroxy-tetramethoxyflavone isomer, while peaks 42, 44, 46 and $47(\mathrm{~m} / \mathrm{z} 359)$ were characterized as trihydroxy-trimethoxyflavone isomers. Compound $\mathbf{4 1}$ was suggested to be 5,7,4'-trihydroxy6,3'-dimethoxyflavone (Jaceosidin) which previously recorded for M. pulegium (Zaidi et al., 1998; Taamalli et al., 2015), while compound $\mathbf{4 6}$ was assigned to be 5,6,4'-trihydroxy-7,8,3'trimethoxyflavone (Thymonin) which previously reported in both species (Zaidi et al., 1998). 


\section{Chemosystematics}

The members of genus Mentha vary from 25-30 (Hajlaoui et al., 2009). According to The plant list (2013), the genus consists of 15 hybrids, 27 basic species, with 14 varieties and subspecies; recently, it's members were grouped in four sections (Kapp, 2015) instead of five (Harley and Brighton, 1977), section Mentha contains five basic species and 11 hybrids where M. longifolia is one of its basic species moreover, the section could be characterized into three lines according to the inflorescence characters (Lawrence, 2007; Brahmi et al., 2017). M. pulegium belongs to section Pulegium; members of the section are characterized by the absence of stolons (Kapp, 2015).

Due to the variation in the levels of ploidy and hybridization of the genus, its infraspecific relationship is complicated and many markers (morphological, cytological and chemical) have been used in studying the systematic relationship of Mentha species (Mint, 2007; Kapp, 2015; Brahmi et al., 2017).

From the flavonoids point of view; the LC-ESI-MS fingerprint of the studied species elucidated that; $M$. pulegium is characterized by presence of rare contents of flavanols (quercetin 3-O-glucoside and rutin) and flavanones (eriocitrin and natirutin) in comparison with flavone compounds which considered the major constituents of M. pulegium extract while in M. longifolia the flavones are predominant followed by flavanols then by only one flavanone compound (natirutin), eriocitrin was isolated before from M. longifolia by Stocker and Pohl (1976) and not detected in the present study. The medioresinol nucleus which distinguished M. longifolia from $M$. pulegium was detected previously in $M$. × piperita L. (Kapp et al. 2013). The presence of caffeic acid and its derivatives in addition to luteolin, apigenin, and their glycosides as a main phenolic constituent in the present study is in agreement with Kapp (2015). The similarity between the two species in synthesis the same phenolic and flavonoidal nucleus moreover the substitution occurs at the same positions make the differentiation between them is too difficult which suggests that M. pulegium and $M$. longifolia could be grouped in the same section.

\section{CONCLUSION}

The present study is a first record on the chemical fingerprint of wild Mentha species grown in Egypt (M. pulegium and $M$. longifolia) using LC-ESI-MS analysis. 43 compounds were identified from the methanolic extracts of the studied species and could be used as taxonomic markers in studying the infraspecific relationship among the genus. Further isolation of metabolites will help in providing more evidence for the possible grouping both species in one section.

\section{ACKNOWLEDGMENT}

This research is funded by the National research centre, Cairo, Egypt; Project number 11010328.

\section{REFERENCES}

Akroum S, Bendjeddou D, Satta D, Lalaoui K. Antibacterial activity and acute toxicity effect of flavonoids extracted from Mentha longifolia. AEJSR, 2009; 4:93-96.

Al-Ali KH, El-Beshbishy HA, El-Badry AA, Alkhalaf M. Cytotoxic activity of methanolic extract of Mentha longifolia and Ocimum basilicum against human breast cancer. PJBS, 2013; 16:1744-50.
Ali MS, Saleem M, Ahmad W, Parvez M, Yamdagni R. A chlorinated monoterpene ketone, acylated $\beta$-sitosterol glycosides and a flavanone glycoside from Mentha longifolia (Lamiaceae). Phytochemistry, 2002; 59:889-95.

Areias FM, Valentao P, Andrade PB, Ferreres F, Seabra RM. Phenolic fingerprint of peppermint leaves. Food Chemistry, 2001; 73(3):307-311.

Baris O, Karadayi M, Yanmis D, Guvenalp Z, Bal T, Gulluce M. Isolation of 3 flavonoids from Mentha longifolia (L.) Hudson subsp. longifolia and determination of their genotoxic potentials by using the E. coli WP2 test system. J. Food Sci, 2011; 76:9.

Brahmi F, Khodir M, Mohamed C, Pierre D. Chemical Composition and Biological Activities of Mentha Species. In Aromatic and Medicinal Plants-Back to Nature. InTech, 2017; 47-80.

Aksit H, Celik SM, Sen Ö, Erenler R, Demirtas I, Telci I, Elmastas M. Complete isolation and characterization of polar portion of Mentha dumetorum water extract. Rec Nat Prod, 2014; 8:277.

Areias FM, Valentao P, Andrade PB, Ferreres F, Seabra RM. Phenolic fingerprint of peppermint leaves. Food Chem, 2001; 73:307-311.

Berdowska I, Zieliński B, Fecka I, Kulbacka J, Saczko J, Gamian A. Cytotoxic impact of phenolics from Lamiaceae species on human breast cancer cells. Food Chem, 2013; 141:1313-1321.

Chen HJ, Inbaraj BS, Chen BH. Determination of phenolic acids and flavonoids in Taraxacum formosanum Kitam by liquid chromatographytandem mass spectrometry coupled with a post-column derivatization technique. Int J Mol Sci, 2011; 13:260-285.

El-Ghorab AH. The chemical composition of the Mentha pulegium L. essential oil from Egypt and its antioxidant activity. J Essent Oil Bear Pl, 2006; 9:183-95.

Farag MA, Otify A, Porzel A, Michel CG, Elsayed A, Wessjohann LA. Comparative metabolite profiling and fingerprinting of genus Passiflora leaves using a multiplex approach of UPLC-MS and NMR analyzed by chemometric tools. Anal Bioanal Chem, 2016; 408:3125-3143.

Gulluce M, Orhan F, Adiguzel A, Bal T, Guvenalp Z, Dermirezer LO. Determination of antimutagenic properties of apigenin-7- $O$-rutinoside, a flavonoid isolated from Mentha longifolia (L.) Huds. ssp. longifolia with yeast DEL assay. Toxicol Ind Health, 2013; 29:534-40.

Gulluce M, Orhan F, Yanmis D, Arasoglu T, Guvenalp Z, Demirezer LO. Isolation of a flavonoid, apigenin 7-O-glucoside, from Mentha longifolia (L.) Hudson subspecies longifolia and its genotoxic potency. Toxicol Ind Health. 2015; 31:831-40.

Guvenalp Z, Ozbek H, Karadayi M, Gulluce M, Kuruuzum-Uz A, Salih B, Demirezer O. Two antigenotoxic chalcone glycosides from Mentha longifolia subsp. longifolia. Pharm Biol, 2015; 53:888-96.

Hajlaoui H, Trabelsi N, Noumi E, Snoussi M, Fallah H, Ksouri R, Bakhrouf A. Biological activities of the essential oils and methanol extract of tow cultivated mint species (Mentha longifolia and Mentha pulegium) used in the Tunisian folkloric medicine. World J Microbiol Biotechnol, 2009; 25:2227-2238.

Harley RM, Brighton CA. Chromosome numbers in the genus Mentha L. Bot J Linn Soc, 1977; 74:71-96.

Hussein SR, Abdel Latif RR, Marzouk MM, Elkhateeb A, Mohammed RS, Soliman AAF, Abdel-Hameed ES. Spectrometric analysis, phenolics isolation and cytotoxic activity of Stipagrostis plumosa (Family Poaceae). Chem Pap, 2018; 72:29-37.

Mint JF. In, Biotechnology in Agriculture and Forestry, Transgenic Crops IV. Pua EC, Davey MR (Eds.), Springer-Verlag Berlin Heidelberg, 2007. Vol. 59.

Kapp K, Hakala E, Orav A, Pohjala L, Vuorela P, Püssa T, Vuorela H, Raal A. Commercial peppermint (Mentha $\times$ piperita L.) teas: Antichlamydial effect and polyphenolic composition. Food Res Int, 2013; 53:758-66.

Kapp K. Polyphenolic and essential oil composition of Mentha and their antimicrobial effect. Faculty of Pharmacy of the University of Helsinki, 2015; 1-73.

Krzyzanowska J, Janda B, Pecio L, Stochmal A, Oleszek W, 
Czubacka A, Przybys M, Doroszewska T. Determination of polyphenols in Mentha longifolia and M. piperita field-grown and in vitro plant samples using UPLC-TQ-MS. Journal of AOAC International, 2011; 94:43-50.

Lawrence BM. Mint: the genus Mentha. Medicinal and aromatic plants-industrial profiles. CRC Press/Taylor \& Francis, Boca Raton, FL. 2007.

Marzouk MM, Hussein SR, Elkhateeb A, Farid MM, Ibrahim LF, Abdel-Hameed ES. Phenolic profiling of Rorippa palustris (L.) Besser (Brassicaceae) by LC-ESI-MS: Chemosystematic significance and cytotoxic activity. Asian Pac J Trop Dis, 2016; 6:633-637.

Mustafa AZ, Badr A, El-Galaly MA, Mobarak AA, Hassan MG. Genetic diversity among Mentha populations in Egypt as reflected by isozyme polymorphism. Int J Bot, 2005; 1:188-195.

Mustafa AM, Badr A, El-Galaly MA, Mobarak AA, Hassan MG. Genetic diversity among Ocimum populations in Egypt as reflected by morphological, seed proteins and isozyme polymorphism. Int J Bot, 2006; $2: 261$.

Naghibi F, Mosaddegh M, Mohammadi Motamed M, Ghorbani A. Labiatae family in folk medicine in Iran: from ethnobotany to pharmacology. Iran J Pharm Res, 2010; 4:63-79.

Ncube EN, Mhlongo MI, Piater LA, Steenkamp PA, Dubery IA, Madala NE. Analyses of chlorogenic acids and related cinnamic acid derivatives from Nicotiana tabacum tissues with the aid of UPLC-QTOFMS/MS based on the in-source collision-induced dissociation method. Chem Cent J, 2014; 8:66.

Orhan F, Barıș Ö, Yanmıș D, Bal T, Güvenalp Z, Güllüce M. Isolation of some luteolin derivatives from Mentha longifolia (L.) Hudson subsp. longifolia and determination of their genotoxic potencies. Food Chem, 2012; 135:764-769.

Püssa T, Raudsepp P, Toomik P, Pällin R, Mäeorg U, Kuusik S, Soidla R, Rei M. A study of oxidation products of free polyunsaturated fatty acids in mechanically deboned meat. J. Food Comp. Anal, 2009; 22:307314 .

Shalaby NMM, Moharram FA, El-Toumy SAA, Marzouk MSA, Ahmed AAE. Phytochemical and pharmacological studies of Mentha pulegium L. Bulletin of Faculty of Pharmacy, Cairo University, Department of Natural Products, National Research Centre, Cairo, Egypt, 2000; 38: $143-151$.
Sharaf M, El-Ansari MA, Saleh NA. Flavone glycosides from Mentha longifolia. Fitoterapia, 1999; 70:478-483.

Shirazi FH, Ahmadi N, Kamalinejad M. Evaluation of northern Iran Mentha pulegium L. cytotoxicity. DARU J Pharm. Sci, 2004; 12:106110 .

Stocker M, Pohl R. Postmortale bildung von 5, 7-dihydroxychromon-7-rutinosid in Mentha longifolia. Phytochemistry, 1976; 15:571-572.

Taamalli A, Arráez-Román D, Abaza L, Iswaldi I, FernándezGutiérrez A, Zarrouk M, Segura-Carretero A. LC-MS-based metabolite profiling of methanolic extracts from the medicinal and aromatic species Mentha pulegium and Origanum majorana. Phytochem Anal, 2015; 26:320-330

Tomás-Barberán FA, Husain SZ, Gil MI. The distribution of methylated flavones in the Lamiaceae. Biochem Syst Ecol, 1988; 16:4346.

Voirin B, Bayet C, Faure O, Jullien F. Free flavonoid aglycones as markers of parentage in Mentha aquatica, M. citrata, M. spicata and $M$. x piperita. Phytochemistry, 1999; 50:1189-1193.

Xu LL, Xu JJ, Zhong KR, Shang ZP, Wang F, Wang RF, Zhang L, Zhang JY, Liu B. Analysis of non-volatile chemical constituents of menthae haplocalycis herba by ultra-high performance liquid chromatography-high resolution mass spectrometry. Molecules, 2017; 22:1756.

Zaidi F, Voirin B, Jay M, Viricel MR. Free flavonoid aglycones from leaves of Mentha pulegium and Mentha suaveolens (Labiatae). Phytochemistry, 1998; 48:991-994.

Zhao GR, Zhang HM, Ye TX, Xiang ZJ, Yuan YJ, Guo ZX, Zhao LB. Characterization of the radical scavenging and antioxidant activities of danshensu and salvianolic acid B. Food Chem Toxicol, 2008; 46:73-81.

How to cite this article:

Marzouk MM, Hussein SR, Elkhateeb A, El-shabrawy M, Abdel-Hameed ES, Kawashty SA. Comparative study of Mentha species growing wild in Egypt: LC-ESI-MS analysis and chemosystematic significance. J App Pharm Sci, 2018; 8(08): 116-122. 